\title{
Do Chronic Stressors Lead to Physiological Dysregulation? Testing the Theory of Allostatic Load
}

\author{
Dana A. Glei, PhD, Noreen Goldman, DSc, Yi-Li Chuang, MPH, and Maxine Weinstein, PhD
}

\begin{abstract}
Objectives: To explore three questions: 1) Do chronic stressors predict physiological dysregulation? 2) Is that relationship moderated by characteristics of the individual and his or her social environment? and 3) Do perceived levels of stress mediate the relationship between stressors and dysregulation? Methods: Data come from a nationally representative, longitudinal study of older Taiwanese $(n=916)$. Regression models are used to examine the relationship between the number of life challenges (i.e., stressors) during 1996 to 2000 and physiological dysregulation (in 2000) based on 16 biomarkers that reflect neuroendocrine function, immune system, cardiovascular function, and metabolic pathways. We include interaction terms to test whether psychosocial vulnerability moderates the impact of stressors. Additional models evaluate the mediating effects of perceived stress. Results: We find a positive association between the number of stressors and physiological dysregulation. The results indicate that this relationship is stronger for persons with greater psychosocial vulnerability, but even so, the magnitude of the effect remains modest. We find some evidence that the level of perceived stress mediates the relationship between chronic stressors and physiological dysregulation. Conclusions: Our results provide some support for the theory of allostatic load, although the relationship between life challenges and physiological dysregulation is weak. The evidence also supports the stress-buffering hypothesis: the combination of low social position, weak social networks, and poor coping ability is associated with greater physiological consequences of life challenges. Key words: chronic stressors, physiological dysregulation, allostatic load, perceived stress, stressful experiences, Taiwan.
\end{abstract}

BMI = body mass index; DHEAS = dehydroepiandrosterone sulfate; HDL = high-density lipoprotein; HPA = hypothalamic-pituitaryadrenal; IGF-1 = insulin-like growth factor 1; IL-6 = interleukin-6; SD = standard deviation; SEBAS = Social Environment and Biomarkers of Aging Study; SEI = socioeconomic index; SNS = sympathetic nervous system; UCL = Union Clinical Laboratories.

\section{INTRODUCTION}

$\mathrm{T}$ he idea that the chronic stressors of contemporary life can have adverse health consequences is receiving increasing attention in both popular and scientific media. The numerous theories that propose possible mechanisms to explain this link all share the sometimes implicit_-perhaps obvious - assumption that there are physiological pathways through which stressors affect health. Most researchers also agree that potentially stressful life events ("stressors") do not affect everyone in the same way.

Our theoretical model (Figure 1) is based on earlier paradigms $(1,2)$ that posit that physiological response to a stressor depends on a person's perception or interpretation. These perceptions, in turn, are shaped by the social environment and individual characteristics. Over time, repeated or prolonged physiological response to life challenges may have a cumulative effect on health. Many studies have tested the link represented by the arrow between physiological dysregulation and health outcomes (Figure 1). There is also a large literature focusing on the overall association between stressors and health outcomes, but relatively few studies examine the intermediate link between chronic stressors and physiological dysregulation (3).

From the Department of Demography (D.A.G.), University of California, Berkeley, Berkeley, California; Office of Population Research (N.G.), Princeton University, Princeton, New Jersey; Center for Population and Health Survey Research (Y.-L.C.), Department of Health, Taiwan; Center for Population and Health (M.W.), Georgetown University, Washington, DC.

Address correspondence and reprint requests to Dana A. Glei, 5985 San Aleso Ct., Santa Rosa, CA 95409-3912. E-mail: danaglei@sonic.net

Received for publication January 10, 2007; revision received July 9, 2007.

This work has been supported by Grants R01AG16790 and R01AG16661 from the Demography and Epidemiology Unit of the Behavioral and Social Research Program of the National Institute of Aging, and by Grant 5P30HD32030 from the National Institute of Child Health and Human Development.

DOI: 10.1097/PSY.0b013e318157cba6
We use longitudinal data from a nationally representative sample of older Taiwanese to examine several pathways through which chronic stressors result in physiological dysregulation. First, we explore the overall association between the number of stressors and physiological dysregulation. Second, we test the interaction implied by Figure 1: do characteristics of individuals and their social environment moderate the effects of these life challenges on physiological dysregulation? Third, we assess whether the relationship between stressors and physiological dysregulation is mediated by perceived levels of stress. Most of what we know about the relationship between stressful experience and physiological response outside the laboratory has been established on the basis of data from Western populations. Here we use measures that are adapted to the Taiwanese context but retain comparability to earlier studies.

\section{What is Allostatic Load and How is it Measured?}

Allostatic load refers to the cumulative cost ("wear and tear") of repeated neuroendocrine response resulting from chronic environmental challenges (4). According to the allostatic load framework, chronic stressors can cause dysregulation of multiple interrelated physiological systems, which if prolonged, may ultimately lead to deteriorations in health $(4,5)$. Such dysregulation is characterized by elevated (or reduced) operating levels of biological parameters that reflect functioning of the sympathetic nervous system (SNS), hypothalamic-pituitary-adrenal (HPA) axis, immune system, and cardiovascular and metabolic processes.

Measures of allostatic load predict diverse health outcomes including cognitive and physical functioning, cardiovascular disease, and mortality (6-10). An initial realization of allostatic load was a simple count of the number of biomarkers out of 10 for which individuals fell into the highest risk quartile (8). More recent formulations incorporate additional biomarkers believed to be associated with the stress response (e.g., inflammatory parameters) and define risk in both tails of the distribution where appropriate (10). 


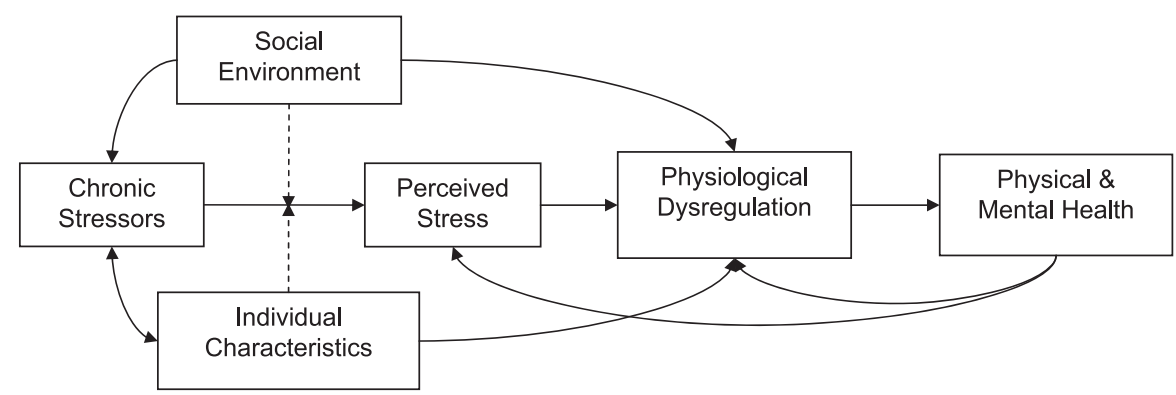

Figure 1. A theoretical model linking chronic stressors and health. Dashed arrows indicate factors that moderate the relationship between stressors and perceived stress.

\section{Link Between Stressful Life Events and Physiology}

Many studies have investigated the relationship between stressors and physical or mental health (11-14), but fewer works address the physiological pathways linking stressful life events to health outcomes. Most studies of physiological parameters focus on the response to acute experimental challenges rather than the long-term effects of chronic stressors.

Few studies have demonstrated an association between stressful life events and a measure of multisystem physiological dysregulation (15-19). Rather, most have focused on individual biological measures believed to be part of the stress response. For example, several studies have found stressful experience to be associated with both higher $(20-22)$ and lower levels of cortisol (23). Whereas some research has demonstrated that life challenges are associated with higher levels of urinary epinephrine or norepinephrine $(22,24)$, others found no such relationship $(21,25)$. Other evidence suggests that life challenges may contribute to higher levels of interleukin-6 (IL-6) (26,27), dehydroepiandrosterone sulfate (DHEAS) (28), blood pressure (29-31), cholesterol (32-34), triglycerides (31), and glycosylated hemoglobin (35-37).

\section{Social Environment and Individual Characteristics as Moderators}

The model shown in Figure 1 implies that characteristics of individuals and their social environment can influence physiological dysregulation a) directly, and b) by moderating the impact of stressors (i.e., "stress-buffering" mechanism) (38). We consider several factors that reflect psychosocial vulnerability to stressors: social connection, social status, personality, and coping skills. Considerable research has documented the impact of social networks and support on health outcomes (39), but only with the recent inclusion of biological markers in social surveys have we been able to explore the effects of the social environment on physiological markers of health. Analyses based on data from Taiwan $(19,40)$ confirm earlier findings from US data regarding the importance of inadequate social support for physiological dysregulation, although the association seems to be weaker than in Western societies $(41,42)$.

Social status may affect both exposure to stressors and access to resources that enable one to effectively cope with those stressors $(2,43)$. Education is a particularly important determinant of social status and upward mobility in Taiwan (44). Elderly Taiwanese adults with no education report higher levels of stress than their educated counterparts (45). Studies in Taiwan find an association between education and physiological dysregulation for women, but not men $(40,46)$.

Individual attributes related to personality and coping skills may also influence perceptions of stressful experience and the physiological impact of stressors (47). For example, optimism is associated with lower levels of subsequent perceived stress $(48,49)$ and better adjustment to stressful events $(50,51)$. Similarly, a sense of personal mastery may moderate the health consequences of stressors $(52,53)$.

\section{METHODS \\ Data}

Our data are from a follow-up of the Survey of Health and Living Status of the Near-Elderly and Elderly in Taiwan. The survey began in 1989 with a national sample of 4049 persons aged $\geq 60$ years (response rate $=92 \%$ ), and was expanded in 1996 to include 2462 persons aged 50 to 66 years in 1996 (response rate $=81 \%$ ). Both cohorts were interviewed in 1999 (response rate $=90 \%$ of survivors)

Among those interviewed in 1999, a random subsample was selected for the 2000 Social Environment and Biomarkers of Aging Study (SEBAS); persons $\geq 71$ years (in 2000) and residents of urban areas were oversampled. SEBAS consisted of an in-home interview and a hospital examination: 1497 persons aged $\geq 54$ years provided interviews in SEBAS ( $92 \%$ of survivors) and 1023 participated in the physical examination (68\% of those interviewed). Of the 474 who did not undergo the examination, 111 were not asked to participate based on exclusion criteria. Disproportionately high nonparticipation rates were found among the healthiest respondents as well as the least healthy, with persons who received the medical examination reporting the same average health status as those who did not. In the presence of controls for age, estimates from the medical examination portion of SEBAS are unlikely to be seriously biased (54).

The Institutional Review Boards of the three participating institutions approved the survey procedures, and written informed consent was obtained for participation in the interview and physical examination. SEBAS respondents who participated in the medical examinations collected a 12-hour overnight urine sample (7 PM to $7 \mathrm{AM}$ ), fasted overnight, and visited a nearby hospital the following morning. Compliance with the urine collection protocol was extremely high. Medical personnel drew a blood sample and took blood pressure and anthropometric measurements during the hospital visit.

\section{Measures}

\section{Physiological Dysregulation}

Blood and urine specimens were analyzed at Union Clinical Laboratories (UCL) in Taipei. In addition to routine standardization and calibration tests performed by the laboratory during the early stages of fieldwork, nine individuals (outside the target sample) contributed triplicate sets of specimens. The results indicate intralaboratory reliability of $\geq 0.86$ for duplicates sent to UCL and interlaboratory correlations of $\geq 0.65$ between results from UCL and Quest Diagnostics (in the US). 
The physiological dysregulation score is based on 16 biomarkers that reflect neuroendocrine, immune system, cardiovascular function, and metabolic pathways. Body mass index (BMI) was calculated as weight divided by height squared $\left(\mathrm{kg} / \mathrm{m}^{2}\right)$ and the waist/hip ratio was based on waist circumference measured at its narrowest point and hip circumference measured at the maximal buttocks. Diastolic and systolic blood pressure measurements were calculated as the average of two seated readings (1 minute apart) taken by a registered nurse (using a mercury sphygmomanometer on the right arm) at least 20 minutes after the respondent arrived at the hospital.

Epinephrine, norepinephrine, dopamine, and cortisol were obtained from the overnight urine specimen, which provides integrated values of these neurotransmitters and hormones for a period when most participants were at home and resting; these markers are reported as micrograms per gram creatinine to adjust for body size. The remaining markers were obtained from the fasting blood specimen: DHEAS, IL-6, insulin-like growth factor 1 (IGF-1), triglycerides, total serum cholesterol, the ratio of total serum cholesterol to high-density lipoprotein (HDL) cholesterol, glycosylated hemoglobin, and fasting glucose. The assays used to measure the biomarkers from the blood and urine samples are described elsewhere (3).

The physiological dysregulation score counts the number of biomarkers for which the individual's value is below the 10th percentile (or below assay sensitivity in the case of epinephrine and IL-6) or above the 90th percentile. For comparability with previous research, we identify elevated risk with only one end of the distribution for DHEAS $(<10 \%)$ and the ratio of total to HDL cholesterol (>90\%).

\section{Number of Stressors}

Surveys in 1996, 1999, and 2000 include extensive information regarding potential stressors and variables that may moderate the effects of stressors. We present results based on one strategy for consolidating these data and provide information about alternative measures in the discussion section.

Our measure of chronic stress is derived from a count of the number of stressors at each wave (1996, 1999, and 2000). Stressors comprise experiences that most people would find anxiety provoking: marital disruption, moving, death of a child, spouse's ill health, financial difficulty, decline in financial position, serious consequences of the 2000 earthquake, and crime/ fraud victimization (data vary across waves) (Appendix Table A1). If data are missing for one of the six stressors in a given wave, we sum across the five valid responses and multiply by 1.2 so that all scores are on the same scale $(0-6)$. Subsequently, we aggregate the number of stressors across all three waves (potential range $=0-18$ ). If data are missing for more than one stressor in any wave, the respondent is excluded from analysis.

\section{Psychosocial Vulnerability}

We incorporate 12 measures that reflect psychosocial vulnerability into our models in two ways. First, we allow for direct associations between physiological dysregulation and each indicator of vulnerability. Second, we construct a summary measure, which we interact with number of stressors to model the stress-buffering mechanism. We use the summary measure rather than individual components of vulnerability in the interaction because we have limited statistical power and because we believe that the presence of one psychosocial resource may compensate for the absence of another. Descriptive statistics for the individual indicators and the summary measure of vulnerability are given in Table 1 .

\section{Social Networks}

Six of our 12 measures of vulnerability relate to social networks and support. In Taiwan, older adults traditionally live with their oldest son; thus, co-residence with adult children may be an important component of social networks. We include whether the respondent lives with his/her child(ren) at the time of the 1996 and 1999 survey waves: neither wave (0), one wave (1), both (2). A second measure, coded in a similar manner (0-2), assesses whether the respondent has weekly contact with at least one nonresident child in 1996 and 1999. Given the importance of the extended family in Taiwanese culture, we measure other social ties separately for relatives and nonrelatives. Two variables count the number of relatives (other than the respondent's
TABLE 1. Descriptive Statistics for Outcome and Covariates, Weighted Estimates

\begin{tabular}{|c|c|}
\hline Variable & Mean (SD) or Percent \\
\hline $\begin{array}{l}\text { Physiological dysregulation in } 2000 \\
\qquad(0-10)\end{array}$ & 3.4 (1.9) \\
\hline $\begin{array}{l}\text { Number of stressors, } 1996-2000 \\
\quad(0-11)\end{array}$ & $2.8 \quad(2.1)$ \\
\hline \multicolumn{2}{|l|}{ Indicators of vulnerability, 1996-2000 } \\
\hline Lives with child (0-2) & $1.4(0.8)$ \\
\hline $\begin{array}{l}\text { Weekly contact with nonresident } \\
\text { child }(0-2)\end{array}$ & $1.5(0.7)$ \\
\hline $\begin{array}{l}\text { Social ties with other relatives } \\
\quad(0-86)\end{array}$ & $24.2(14.3)$ \\
\hline $\begin{array}{l}\text { Social ties with close friends and } \\
\text { neighbors }(0-70)\end{array}$ & $13.4(11.0)$ \\
\hline Number of social activities (0-14) & $3.4(2.4)$ \\
\hline Index of emotional support (0.9-4) & $3.1 \quad(0.6)$ \\
\hline $\begin{array}{l}\text { Years of education completed } \\
(0-17)\end{array}$ & $5.3(4.6)$ \\
\hline Socioeconomic index (55.1-76.1) & $61.6(4.7)$ \\
\hline Locus of control index (0-3) & $1.6(0.5)$ \\
\hline Engagement $(0-4)$ & $3.2(1.0)$ \\
\hline Optimism $(0-2)$ & $1.6(0.5)$ \\
\hline $\begin{array}{l}\text { Index of advantages of growing old } \\
(0-3)\end{array}$ & $1.6(0.6)$ \\
\hline $\begin{array}{l}\text { Summary measure of vulnerability } \\
\quad(-16.6 \text { to } 16.8)\end{array}$ & $-0.9 \quad(5.0)$ \\
\hline Perceived stress index, $2000(0-13)$ & $1.7 \quad(2.5)$ \\
\hline Percent female & 41.8 \\
\hline Age in 2000 (54-91) & $66.1(7.8)$ \\
\hline Percent urban residence & 44.0 \\
\hline Number of respondents & 851 \\
\hline
\end{tabular}

The observed range is shown in parentheses.

children) and nonrelatives with whom the respondent reports having regular contact; we sum the number of these ties across 1996 and 1999 waves.

Respondents were asked about 11 types of social activities that are common in Taiwan: 1) playing games (e.g., mahjong); 2) chatting with relatives, friends, or neighbors or drinking tea socially; 3) group activities (e.g., Tai Chi); 4) doing volunteer work; and participating in 5) religious associations, 6) professional groups (e.g., farmer's association), 7) political groups, 8) village or lineage associations, 9) elderly clubs, 10) neighborhood associations, and 11) social service groups. For 1996 and 1999, we count the number of these activities the respondent participated in if at least nine items have valid responses (if one or two items are missing, we sum across valid items, divide by the number of valid items, and multiply by 11 so that the scale is the same for all respondents). We sum the number of activities across waves (potential range $=0-22$ ).

Emotional support is assessed in 1996 and 1999 from questions asking respondents how willing others are to listen to them, take care of them when they are ill, make them feel loved and cared for, and how satisfied they are with the overall level of emotional support received; each item is coded on a 0 to 4 scale. An index is created by summing the two sets of four items and dividing by the number of valid items (if at least six items are valid); range is 0 to 4 , and $\alpha$ reliability is 0.84 .

\section{Position in Social Hierarchies}

Two indicators reflect social position: the respondent's education and a socioeconomic index (SEI) for the major lifetime occupation of the respondent (if male) or (most recent) spouse (if female). The SEI was developed by Tsai and Chiu (55) specifically for Taiwan using a strategy applied by Duncan (56) and Featherman and Stevens (57) to the US. The score ranges from 55.1 for farm laborers to 76.1 for doctors and is missing for the two female respondents who never married. 


\section{Internal Resources}

Four indicators relate to individual characteristics that may affect one's ability to cope with stressors. Locus of control is based on five items (coded $0-4)$ from the Pearlin scale (58) included in the 2000 interview. The index is computed by summing across items (if at least four are valid) and dividing by the number of valid items (range $=0-3$, where $3=$ greater personal mastery); the $\alpha$ reliability is 0.73 .

Engagement is based on two questions asked in 1996 and 1999: "Do you find what you do interesting?" and "Do you feel that most of what you do is monotonous and of no interest?" We assign 1 point each for a "yes" response to the first and a "no" to the second question, and then sum across both waves (range $=0-4$ ).

Optimism is based on the following question asked in 1996 and 1999: "Do you expect that in the future happy things will occur?" One point is assigned for each "yes" response (range $=0-2$ ).

In 1996, respondents were asked to rate (4-point scale) the importance of seven advantages of growing old (e.g., can spend more time with spouse and/or children). If an item is not applicable (e.g., respondent does not have a spouse), it is coded 0 . The items are summed (if at least 5 items are valid) and divided by the number of valid items (range $=0-3$, where $3=$ more positive view of growing old); the $\alpha$ reliability is 0.75 .

\section{Overall Vulnerability}

Using the 12 vulnerability indicators, we create a summary measure by: 1) reverse-coding each variable so that higher values indicate greater vulnerability; 2) standardizing each indicator to have a mean of 0 and standard deviation (SD) of 1 ; and 3) summing across all indicators (range $=-16.6$ to 16.8 ).

\section{Perceived Stress}

Perceived stress is based on the respondent's report (in 2000) of whether each of seven situations "makes you feel stressed or anxious." Three of these situations refer to the respondent's life (own financial situation, job, and getting along with family members), and an additional four items pertain to family (the family's or children's health, financial situation, job, and marital situation). Each item is coded on a 3-point scale: no (0), some (1), a lot of stress (2). "Not applicable" responses are assigned a value of 0 . The index is calculated by summing across all items if there are at least six valid items: if one is missing, we rescale the index using a multiplier of $7 / 6$. The potential range for this index is 0 to 14 ; the $\alpha$ reliability is 0.78 .

\section{Control Variables}

Demographic controls include age, sex, and urban residence. Age is measured as of the 2000 interview based on the respondent's reported date of birth.

\section{Analytical Strategy}

The analysis sample consists of 851 SEBAS participants, excluding 10 participants missing data on at least one of the biomarkers, 53 for whom a proxy completed one of the interviews, and 109 who were missing one of the covariates. Descriptive statistics shown in Table 1 are weighted to compensate for oversampling by age and urban residence.

For regression models, we use a robust estimator of variance and adjust for clustering by primary sampling units to produce corrected standard errors (59). Using a linear model, we first regress the physiological dysregulation score on the number of stressors and control variables. In the second model, we add the individual indicators of vulnerability as main effects and the interaction term between overall vulnerability (which is a linear combination of the individual variables) and number of stressors. The third model adds the index of perceived stress.

Finally, we estimate two linear models using the perceived stress index as the dependent variable. These models include the same covariates described above for models 1 and 2, respectively.

\section{RESULTS}

The mean physiological dysregulation score was 3.4 and the mean number of stressors across the waves was 2.8 (Table
1). On average, this sample scored $1.7($ possible score $=14)$ on the perceived stress index.

Results from models predicting physiological dysregulation are presented in Table 2. Model 1 confirms a significant association between number of stressors and physiological dysregulation, although the magnitude is small: a 1-SD increase in stressors (2.1 additional stressors) is associated with a 0.09 -SD increase in the dysregulation score $(0.17)$.

Model 2 tests for the main effects and stress-moderating influences. Among the 12 indicators of psychosocial vulnerability, only one of the main effects is statistically significant: a stronger internal locus of control is associated with lower levels of dysregulation. The coefficient of the interaction term indicates that the relationship between the number of stressors and dysregulation is stronger among those with greater vulnerability, but the effect remains small. For example, for a person whose vulnerability score is $1 \mathrm{SD}$ above the mean, a 1 -SD increase in stressors is associated with a $0.11-S D$ increase in dysregulation.

Model 3 investigates whether perceived stress mediates the effects of stressors on dysregulation. If so, we would expect the coefficients associated with the number of stressors to be substantially attenuated after adding perceived stress to the model. The results show limited evidence of such mediating effects: the magnitude of the main effect for stressors shrinks to virtually nil, but there is little change in the interaction effect. We find a direct relationship between perceived stress and physiological dysregulation as implied by Figure 1, but again the magnitude is small: a 1-SD increase in the perceived stress index is associated with a 0.12 -SD increase in the dysregulation score.

If perceived stress mediates the effects of stressors on dysregulation, there should also be a direct relationship between stressors and perceived stress (Figure 1). The estimates from model 1 of Table 3 confirm the expected positive relationship between the number of stressors and perceived stress. However, in model 2, we find no evidence that the relationship between stressors and perceived stress is conditioned by the level of vulnerability.

\section{DISCUSSION}

Because the key variables in our models could have been defined in many ways, we carried out extensive exploratory analyses to assess the robustness of our results. First, we tested several ways of modeling stressors (e.g., grouping stressors by domain, time period, or duration). Second, we explored alternative specifications for vulnerability (e.g., summary measures for the three domains of vulnerability, categorical measures of vulnerability). Third, we tested for a nonlinear relationship between stressors and physiological dysregulation. Finally, we performed analyses that incorporated additional waves (1989 and 1993) of the survey based on persons $>70$ years old. Our results changed little across these alternative specifications.

The findings suggest that the combination of low social position, weak social networks, and limited internal resources can render individuals more vulnerable to the adverse conse- 
TABLE 2. Coefficients from Linear Regression Models Predicting Physiological Dysregulation

\begin{tabular}{|c|c|c|c|c|c|}
\hline & (1) & & (2) & & (3) \\
\hline Female & $0.584^{*}[0.276,0.892]$ & $0.443^{*}$ & {$[0.132,0.753]$} & $0.443^{*}$ & {$[0.133,0.753]$} \\
\hline Age & $0.012[-0.003,0.026]$ & 0.007 & {$[-0.011,0.025]$} & 0.011 & {$[-0.007,0.030]$} \\
\hline Number of stressors & $0.080 *[0.028,0.131]$ & 0.039 & {$[-0.019,0.098]$} & 0.002 & {$[-0.065,0.070]$} \\
\hline $\begin{array}{l}\text { Number of stressors } \times \text { overall vulnerability } \\
\text { Indicators of vulnerability }\end{array}$ & - & $0.013^{* *}$ & {$[0.002,0.024]$} & $0.012^{* *}$ & {$[0.001,0.024]$} \\
\hline Social ties with other relatives & - & 0.001 & {$[-0.011,0.013]$} & 0.002 & {$[-0.010,0.014]$} \\
\hline Social ties with friends and neighbors & - & 0.001 & {$[-0.009,0.011]$} & 0.000 & {$[-0.010,0.010]$} \\
\hline Number of social activities & - & -0.008 & {$[-0.056,0.041]$} & -0.005 & {$[-0.055,0.044]$} \\
\hline Index of emotional support & - & 0.176 & {$[-0.101,0.454]$} & 0.191 & {$[-0.078,0.460]$} \\
\hline Years of education completed & - & -0.008 & {$[-0.053,0.037]$} & -0.008 & {$[-0.053,0.036]$} \\
\hline Index of advantages of growing old & - & -0.136 & {$[-0.313,0.041]$} & $-0.162^{\dagger}$ & {$[-0.338,0.013]$} \\
\hline Perceived stress index & - & & - & $0.092 *$ & {$[0.038,0.146]$} \\
\hline Constant & $2.229 *[1.190,3.269]$ & $2.702^{\dagger}$ & {$[-0.317,5.720]$} & 2.203 & {$[-0.750,5.157]$} \\
\hline $\mathrm{R}^{2}$ & .04 & & .06 & & .07 \\
\hline
\end{tabular}

The $95 \%$ confidence intervals are shown in brackets next to each coefficient.

${ }^{\dagger} p<.10 ; * * p<.05 ; * p<.01$.

TABLE 3. Coefficients From Linear Regression Models Predicting Perceived Stress

\begin{tabular}{|c|c|c|c|}
\hline & (1) & & $(2)$ \\
\hline Female & $0.139[-0.217,0.494]$ & -0.007 & {$[-0.449,0.436]$} \\
\hline Age & $-0.046^{*}[-0.063,-0.028]$ & $-0.049 *$ & {$[-0.066,-0.031]$} \\
\hline Urban residence & $-0.071[-0.654,0.512]$ & -0.066 & {$[-0.535,0.404]$} \\
\hline Number of stressors & $0.510 *[0.391,0.629]$ & $0.401^{*}$ & {$[0.272,0.531]$} \\
\hline Number of stressors $\times$ overall vulnerability & - & 0.007 & {$[-0.017,0.030]$} \\
\hline \multicolumn{4}{|l|}{ Indicators of vulnerability } \\
\hline Number waves living with child & - & 0.158 & {$[-0.035,0.352]$} \\
\hline Number waves weekly contact with nonresident child & - & 0.208 & {$[-0.063,0.480]$} \\
\hline Social ties with other relatives & - & -0.011 & {$[-0.024,0.003]$} \\
\hline Social ties with friends and neighbors & - & 0.008 & {$[-0.007,0.024]$} \\
\hline Number of social activities & - & -0.023 & {$[-0.077,0.031]$} \\
\hline Index of emotional support & - & -0.161 & {$[-0.454,0.132]$} \\
\hline Years of education completed & - & 0.000 & {$[-0.044,0.043]$} \\
\hline Socioeconomic Index & - & -0.006 & {$[-0.035,0.022]$} \\
\hline Locus of control index & - & $-0.491^{*}$ & {$[-0.797,-0.186]$} \\
\hline Engagement & - & $-0.314^{\star}$ & {$[-0.481,-0.148]$} \\
\hline Optimism & - & 0.182 & {$[-0.144,0.508]$} \\
\hline Index of advantages of growing old & - & $0.290^{\dagger}$ & {$[-0.026,0.606]$} \\
\hline Constant & $3.317^{*}[2.166,4.467]$ & $5.413^{*}$ & {$[2.679,8.148]$} \\
\hline $\mathrm{R}^{2}$ & .22 & & .26 \\
\hline
\end{tabular}

The $95 \%$ confidence intervals are shown in brackets next to each coefficient.

${ }^{\dagger} p<.10 ; * p<.01$.

quences of life challenges, although the magnitude of the association is small. Auxiliary analyses (not shown) demonstrate that this finding is robust to the inclusion of baseline controls for mobility limitations, cognitive function, and depressive symptoms. Although these results indicate a stressbuffering mechanism, we find little evidence that components of vulnerability are directly associated with physiological dys- regulation. This distinction between direct and moderating effects is important for researchers developing theoretical models describing the linkages among the social environment, life challenges, and biological response.

We propose several alternative explanations for the weak relationship between stressors and physiological dysregulation. First, it is impossible to retrospectively construct an 
accurate, detailed picture of lifetime exposure to stressors in a large-scale survey of an older population. A second factor is sample attrition- because of the strong association between physiological dysregulation and survival (6), individuals with the greatest lifetime exposure to stressors and the highest vulnerability are more likely than others to have died before the most recent interview and, thus, to have been excluded from the sample. Additional analyses indicate that 1) individuals with a greater number of stressors in 1996 were more likely to die by 2000; and 2) among survivors with higher levels of vulnerability, stressors were inversely associated with completion of the examination. To further explore the effects of attrition, we fit a logit model with the outcome variable equal to one for those who died between 1996 and $2000(n=543)$ or those who scored $\geq 4$ on dysregulation in $2000(n=415)$ and zero for those who scored $<4$ on dysregulation $(n=486)$. Results (not shown) indicate that the number of stressors in 1996 has a stronger association when deaths are included (odds ratio $(\mathrm{OR})=1.21 ; p<.001$ ) than when deaths are excluded $(\mathrm{OR}=1.12)$. This evidence suggests that mortality (and perhaps other attrition) leads us to underestimate the magnitude of the association between stressors and dysregulation.

Our measure of physiological dysregulation has several limitations: 1) it excludes physiological and genetic markers that are likely to be important components of the stress response, some of which are impossible to measure in this type of fieldwork; 2) the designations for high and low values on many of the markers are arbitrary because little is known about appropriate cut-offs; 3) SEBAS collected these biomarkers at a single time; and 4) a dysregulation score that combines numerous biomarkers may obscure important relationships with individual measures. The last issue is a major shortcoming that characterizes all measures of allostatic load.

Although we attempted to construct culturally appropriate measures that were analogous to measures used in a Western context, our identification of a weak relationship between life challenges and physiological dysregulation in Taiwan may not be generalizable to other non-Western contexts or to other populations. We expected that the central role of family in Taiwanese social interactions would be reflected in the importance of co-residence or contact with children and other family members, but we found no evidence to support the idea that familial ties matter more than nonfamilial ties. We have speculated elsewhere (40) that the emphasis on familial ties may result in high overall levels of social integration in Taiwan, in turn resulting in lower vulnerability relative to more individualistic Western populations. We also recognize that we have not fully captured the cultural context in our statistical models.

Our results suggest that the association between stressors and physiological dysregulation we do observe in Taiwan is not fully mediated by perceived stress, perhaps because our index of perceived stress (measured in 2000) does not adequately reflect the effect of challenges in earlier years, or perhaps because respondents are unwilling to report negative emotions to interviewers. An alternative explanation is that life events may have physiological consequences even if individuals do not perceive them as stressful.

The relationship between life challenges and physiological response proposed by the theory of allostatic load cannot be tested in a laboratory. Despite the difficulty of collecting the requisite biological and experiential information, such an analysis requires observational data from a population-based sample. SEBAS provides a rare opportunity to evaluate the hypothesized link between chronic stressors and allostatic load. Our results suggest that efforts to improve psychosocial resources may reduce an individual's vulnerability to adverse physiological consequences of stressors, although the impact may be small. A second wave of SEBAS, completed in early 2007, provides additional biological measures associated with the stress response as well as reports of traumatic experiences, major life events, daily hassles, and stress-reducing activities that will enable us to investigate these relationships further.

We thank Amy Love Collins for her helpful comments on this paper. We also thank Germán Rodriguez and John Hobcraft for their statistical advice at early stages of the analysis.

\section{Appendix}

TABLE A1. Descriptive Statistics for Individual Stressors, Weighted Estimates

\begin{tabular}{|c|c|c|c|}
\hline \multirow{2}{*}{ Variable } & \multicolumn{3}{|c|}{ Mean (SD) or Percent } \\
\hline & 1996 & 1999 & 2000 \\
\hline \multicolumn{4}{|l|}{ Stressors } \\
\hline Percent with marital disruption ${ }^{a}$ & 20.9 & 3.1 & 2.3 \\
\hline $\begin{array}{l}\text { Percent who have moved to a } \\
\text { new residence }{ }^{b}\end{array}$ & 8.4 & 7.8 & 2.8 \\
\hline Percent whose child died ${ }^{a}$ & 12.8 & 1.8 & - \\
\hline $\begin{array}{l}\text { Percent with spouse in not so } \\
\text { good or poor health }\end{array}$ & 19.5 & 14.8 & 18.1 \\
\hline $\begin{array}{l}\text { Percent with difficulty meeting } \\
\text { living expenses }\end{array}$ & 20.9 & 28.1 & 26.0 \\
\hline $\begin{array}{l}\text { Percent financially worse off } \\
\text { than three years ago }\end{array}$ & 25.1 & 31.7 & - \\
\hline Percent affected by earthquake ${ }^{c}$ & - & - & 23.9 \\
\hline $\begin{array}{l}\text { Percent respondent/spouse/ } \\
\text { children victimized by crime/ } \\
\text { fraud in the past year }\end{array}$ & - & - & 11.5 \\
\hline Mean number of stressors $(0-5)$ & $1.1(1.0)$ & $0.9(1.0)$ & $0.8(0.9)$ \\
\hline
\end{tabular}

The observed range is shown in parentheses.

${ }^{a}$ Indicates the proportion who have ever experienced the event (by 1996) or who have experienced this event from the time of the previous survey wave (as of 1999 and 2000).

${ }^{b}$ In the past 3 years (as of 1996) or from the time of the previous survey (as of 1999 and 2000).

${ }^{c}$ Earthquake (in 2000) resulted in injury to the respondent, injury/death to family or close friend, temporary displacement, or damage to home or other property. 


\section{REFERENCES}

1. Cohen S, Kessler RC, Gordon LU. Strategies for measuring stress in studies of psychiatric and physical disorders. In: Cohen S, Kessler RC, Underwood Gordon L, editors. Measuring Stress, a Guide for Health and Social Scientists. New York: Oxford University Press; 1997.

2. House JS. Understanding social factors and inequalities in health: 20th century progress and 21 st century prospects. J Health Soc Behav 2002; 43:125-42.

3. Goldman N, Glei DA, Seplaki C, Liu IW, Weinstein M. Perceived stress and physiological dysregulation in older adults. Stress 2005;8:95-105.

4. McEwen BS, Stellar E. Stress and the individual. Mechanisms leading to disease. Arch Intern Med 1993;153:2093-101.

5. McEwen BS. Sex, stress and the hippocampus: allostasis, allostatic load and the aging process. Neurobiol Aging 2002;23:921-39.

6. Goldman N, Turra CM, Glei DA, Lin YH, Weinstein M. Physiological dysregulation and changes in health in an older population. Exp Gerontol 2006;41:862-70.

7. Karlamangla AS, Singer BH, McEwen BS, Rowe JW, Seeman TE. Allostatic load as a predictor of functional decline. J Clin Epidemiol 2002;55:696-710.

8. Seeman TE, Singer BH, Rowe JW, Horwitz RI, McEwen BS. Price of adaptation-allostatic load and its health consequences. MacArthur studies of successful aging. Arch Intern Med 1997;157:2259-68.

9. Seeman TE, McEwen BS, Rowe JW, Singer BH. Allostatic load as a marker of cumulative biological risk: MacArthur studies of successful aging. Proc Natl Acad Sci U S A 2001;98:4770-5.

10. Seplaki CL, Goldman N, Glei D, Weinstein M. A comparative analysis of measurement approaches for physiological dysregulation in an older population. Exp Gerontol 2005;40:438-49.

11. Maddock C, Pariante CM. How does stress affect you? An overview of stress, immunity, depression and disease. Epidemiol Psychiatr Soc 2001; 10:153-62.

12. Chong MY, Tsang HY, Chen CS, Tang TC, Chen CC, Yeh TL, Lee YH, Lo HY. Community study of depression in old age in Taiwan: prevalence, life events and socio-demographic correlates. Br J Psychiatry 2001;178: $29-35$.

13. Kraaij V, Arensman E, Spinhoven P. Negative life events and depression in elderly persons: a meta-analysis. J Gerontol Series B-Psychol Sci Soc Sci 2002;57:P87-P94.

14. Beckett M, Goldman N, Weinstein M, Lin IF, Chuang YL. Social environment, life challenge, and health among the elderly in Taiwan. Soc Sci Med 2002;55:191-209.

15. Clark MS, Bond MJ, Hecker JR. Environmental stress, psychological stress and allostatic load. Psychol Health Med 2007;12:18-30.

16. Evans GW. A multimethodological analysis of cumulative risk and allostatic load among rural children. Dev Psychol 2003;39:924-33.

17. Gersten O. Neuroendocrine biomarkers, social relations, and the costs of cumulative stress in Taiwan. Soc Sci Med, In Press.

18. Schnorpfeil P, Noll A, Schulze R, Ehlert U, Frey K, Fischer JE. Allostatic load and work conditions. Soc Sci Med 2003;57:647-56.

19. Weinstein M, Goldman N, Hedley A, Yu-Hsuan L, Seeman T. Social linkages to biological markers of health among the elderly. J Biosoc Sci 2003;35:433-53.

20. Davis LL, Weaver M, Zamrini E, Stevens A, Kang DH, Parker CR Jr. Biopsychological markers of distress in informal caregivers. Biol Res Nurs 2004;6:90-9.

21. Powell LH, Lovallo WR, Matthews KA, Meyer P, Midgley AR, Baum A, Stone AA, Underwood L, McCann JJ, Janikula Herro K, Ory MG. Physiologic markers of chronic stress in premenopausal, middle-aged women. Psychosom Med 2002;64:502-9.

22. Schaeffer MA, Baum A. Adrenal cortical response to stress at Three Mile Island. Psychosom Med 1984;46:227-37.

23. Miller GE, Cohen S, Ritchey AK. Chronic psychological stress and the regulation of pro-inflammatory cytokines: a glucocorticoid-resistance model. Health Psychol 2002;21:531-41.

24. Babisch W, Fromme H, Beyer A, Ising H. Increased catecholamine levels in urine in subjects exposed to road traffic noise: the role of stress hormones in noise research. Environ Int 2001;26:475-81.

25. Vingerhoets AJ, Ratliff-Crain J, Jabaaij L, Tilders FJ, Moleman P, Menges LJ. Self-reported stressors, symptom complaints and psychobiological functioning-II: Psychoneuroendocrine variables. J Psychosom Res 1996;40:191-203.

26. Lutgendorf SK, Garand L, Buckwalter KC, Reimer TT, Hong SY,
Lubaroff DM. Life stress, mood disturbance, and elevated interleukin-6 in healthy older women. J Gerontol A Biol Sci Med Sci 1999;54: M434-M439.

27. Kiecolt-Glaser JK, Preacher KJ, MacCallum RC, Atkinson C, Malarkey WB, Glaser R. Chronic stress and age-related increases in the proinflammatory cytokine IL-6. Proc Natl Acad Sci U S A. 2003;100:9090-5.

28. Bernton E, Hoover D, Galloway R, Popp K. Adaptation to chronic stress in military trainees. Adrenal androgens, testosterone, glucocorticoids, IGF-1, and immune function. Ann N Y Acad Sci 1995;774:217-31.

29. Brand N, Hanson E, Godaert G. Chronic stress affects blood pressure and speed of short-term memory. Percept Mot Skills 2000;91:291-8.

30. Cacioppo JT, Burleson MH, Poehlmann KM, Malarkey WB, KiecoltGlaser JK, Berntson GG, Uchino BN, Glaser R. Autonomic and neuroendocrine responses to mild psychological stressors: effects of chronic stress on older women. Ann Behav Med 2000;22:140-8.

31. Su CT, Yang HJ, Lin CF, Tsai MC, Shieh YH, Chiu WT. Arterial blood pressure and blood lipids as cardiovascular risk factors and occupational stress in Taiwan. Int J Cardiol 2001;81:181-7.

32. Coleman CA, Friedman AG, Burright RG. The relationship of daily stress and health-related behaviors to adolescents' cholesterol levels. Adolescence 1998;33:447-60.

33. Roglic G, Metelko Z. Effect of war on glycemic control in type II diabetic patients. Diabetes Care 1993;16:806-8.

34. Stoney CM, Niaura R, Bausserman L, Matacin M. Lipid reactivity to stress: I. Comparison of chronic and acute stress responses in middleaged airline pilots. Health Psychol 1999;18:241-50.

35. Goldston DB, Kovacs M, Obrosky DS, Iyengar S. A longitudinal study of life events and metabolic control among youths with insulin-dependent diabetes mellitus. Health Psychol 1995;14:409-14.

36. Lloyd CE, Dyer PH, Lancashire RJ, Harris T, Daniels JE, Barnett AH. Association between stress and glycemic control in adults with type 1 (insulin-dependent) diabetes. Diabetes Care 1999;22:1278-83.

37. Griffith LS, Field BJ, Lustman PJ. Life stress and social support in diabetes: association with glycemic control. Int J Psychiatry Med 1990; 20:365-72.

38. Cohen S. Social relationships and health. Am Psychol 2004;59:676-84.

39. Seeman TE, Crimmins E. Social environment effects on health and aging: integrating epidemiologic and demographic approaches and perspectives. Ann N Y Acad Sci 2001;954:88-117.

40. Seeman T, Glei D, Goldman N, Weinstein M, Singer B, Lin YH. Social relationships and allostatic load in Taiwanese elderly and near elderly. Soc Sci Med 2004;59:2245-57.

41. Seeman TE, Singer BH, Ryff CD, Dienberg Love G, Levy-Storms L. Social relationships, gender, and allostatic load across two age cohorts. Psychosom Med 2002;64:395-406.

42. Singer B, Ryff CD. Hierarchies of life histories and associated health risks. Ann N Y Acad Sci 1999;896:96-115.

43. Pearlin LI, Schieman S, Fazio EM, Meersman SC. Stress, health, and the life course: some conceptual perspectives. J Health Soc Behav 2005;46: 205-19.

44. Fricke T, Chang JS, Yang LS. Historical and ethnographic perspectives on the Chinese family. In: Thornton A, Lin HS, editors. Social Change and the Family in Taiwan. Chicago: University of Chicago Press; 1994.

45. Wang JJ, Snyder M, Kaas M. Stress, loneliness, and depression in Taiwanese rural community-dwelling elders. Int J Nurs Stud 2001;38: $339-47$.

46. Dowd JB, Goldman N. Do biomarkers of stress mediate the relation between socioeconomic status and health? J Epidemiol Community Health 2006;60:633-9.

47. Biondi M, Picardi A. Psychological stress and neuroendocrine function in humans. Psychother Psychosom 1999;68:114-50.

48. Brissette I, Scheier MF, Carver CS. The role of optimism in social network development, coping, and psychological adjustment during a life transition. J Pers Soc Psychol 2002;82:102-11.

49. Segerstrom SC, Taylor SE, Kemeny ME, Fahey JL. Optimism is associated with mood, coping, and immune change in response to stress. J Pers Soc Psychol 1998;74:1646-55.

50. Carver CS, Smith RG, Antoni MH, Petronis VM, Weiss S, Derhagopian RP. Optimistic personality and psychosocial well-being during treatment predict psychosocial well-being among long-term survivors of breast cancer. Health Psychol 2005;24:508-16.

51. Kivimaki M, Vahtera J, Elovainio M, Helenius H, Singh-Manoux A, Pentti J. Optimism and pessimism as predictors of change in health after death or onset of severe illness in family. Health Psychol 2005;24:413-21. 
52. Bovier PA, Chamot E, Perneger TV. Perceived stress, internal resources, and social support as determinants of mental health among young adults. Qual Life Res 2004;13:161-70.

53. Pudrovska T, Schieman S, Pearlin LI, Nguyen K. The sense of mastery as a mediator and moderator in the association between economic hardship and health in late life. J Aging Health 2005;17:634-60.

54. Goldman N, Lin IF, Weinstein M, Lin YH. Evaluating the quality of self-reports of hypertension and diabetes. J Clin Epidemiol 2003;56: $148-54$.

55. Tsai SL, Chiu HY. Constructing Occupational Scales for Taiwan. Research in Social Stratification and Mobility 1991;10:229-53.
56. Duncan OD. A socioeconomic index for all occupations. In: Reiss AJ, editor. Occupations and Social Status. New York: Free Press; 1961.

57. Featherman DL, Stevens G. A revised socio-economic index of occupational status: application in analysis of sex differences in attainment. In: Hauser RM, Mechanic D, Haller AO, Hauser TS, editors. Social Structure and Behavior: Essays in Honor of William Hamilton Sewell. New York: Academic Press; 1982.

58. Pearlin LI, Lieberman MA, Menaghan EG, Mullan JT. The stress process. J Health Soc Behav 1981;22:337-56.

59. StataCorp. Stata User's Guide: release 9.0. College Station, TX: Stata Corporation; 2005. 